\title{
Schmincke's Tumor, Carcinoma of the Base of the Tongue c T1-2, cN2c M0 - A Case Report
}

\section{H. Merz ${ }^{\mathrm{a}} \quad$ S. Marnitz ${ }^{\mathrm{b}} \quad$ A. Erbersdobler $\quad$ O. Goektas ${ }^{\mathrm{a}}$}

${ }^{a}$ Klinik für Hals-, Nasen-, Ohrenheilkunde, Charité Campus Mitte, ${ }^{b}$ Charité Campus Mitte und CVK Klinik für Strahlentherapie, and Institut für Pathologie, Charité Campus Mitte, Berlin, Germany

\section{Key Words}

Schmincke's tumor - Oropharynx - Base of tongue

\begin{abstract}
Background: Lymphoepithelial tumors are the most common carcinomas of the nasopharynx. The non-differentiated tumor, also called Schmincke's tumor, is more prevalent in the African and Chinese population. The incidence of the tumor according to age peaks between 20 and 30 years of age, and after 60 years of age. The tumor is rarely located outside of the nasopharynx.
\end{abstract}

Case Report: This report is about a 73-year-old female patient diagnosed with a tumor of the base of the tongue. The histological result shows a low-grade carcinoma of the squamous epithelium, a lymphoepithelial carcinoma.

Conclusion: Despite the tumor's rare manifestation outside the nasopharynx, one must also consider the non-differentiated carcinoma of lymphoepithelial matrix. Especially due to the well-known early tumor spreading, cervical lymph node swelling on both sides can be recognized as a possible early symptom. First-line therapy consists of primary radiation of the tumor's primary region and its lymphoid draining channels. Concomitant chemotherapy can be applied. In case of cervical tumor spreading, a neck dissection reduces the risk of local recurrence.

\section{Introduction}

Lymphoepithelial tumors represent $30 \%$ of all malignant tumors of the nasopharynx. The tumor is rarely located outside of the nasopharynx. There are only individual case reports referring to these external locations $[1,3,4,6,9]$. Hereby an infection with the oncogenic Epstein Barr virus seems to play a role [5]. 


\begin{tabular}{|c|c|c|c|}
\hline $\begin{array}{c}\text { Cose Reports in } \\
\text { Onacily }\end{array}$ & $\begin{array}{l}\text { Case Rep Oncol 2010;3:77-82 } \\
\text { Dol: } 10.1159 / 000302139\end{array}$ & Published online: March 24, 2010 & \begin{tabular}{|l} 
@ 2010 S. Karger AG, Basel \\
ISSN 1662-6575 \\
www.karger.com/cro
\end{tabular} \\
\hline
\end{tabular}

\section{Case Report}

\section{History}

A 73-year-old woman was complaining about a sore throat lasting for already 8 weeks, accompanied by lymph node swelling. The patient was admitted to hospital for an endoscopic examination as well as for a biopsy to exclude a malignancy. The past medical history shows a carcinoma of the sigma in 1978.

\section{Medical Findings and Diagnostic Investigations}

The ENT medical findings revealed a minor asymmetrical hyperplasia of the base of the tongue. It was possible to palpate an induration on the right side of the base of the tongue next to the

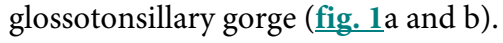

The remaining physical ENT examination was unremarkable, except for palpable lymph node swelling on both sides. A cervical CT shows multiple augmented lymph nodes on the right side. Three suspicious lymph nodes of level II, and one more of level III/IV, were seen in the following sonography. Likewise, on the left side, there was also a suspicious node of $1 \mathrm{~cm}$ in diameter of level II.

The histological result was a lymphoepithelial mucosa of the base of the tongue with a subepithelial infiltration of medium-sized, atypical, blastary cells with vesicular cores (fig. 2). The latter showed an immunohistological expression of pan-cytokeratin (fig. 3 ), although there is no positive index for Blymphocytes (CD 40) and T-lymphocytes (CD 2). T-lymphocytes were positive in little lymphocytes, which appear rarely in between the tumor cells. There was no development of desmoplasmatic stroma. A low-grade differentiated, non-keratinizing carcinoma of the type lymphoepithelial carcinoma was diagnosed. The specimen preparation taken from the left side of the base of the tongue was free of tumor cells. Also DNA was extracted for finding specific sequences by PCR examination. Evidence of a virus genome of Epstein Barr was discovered. CT scan of the chest and sonography of the abdomen excluded tumor spreading.

\section{Therapy and Progress}

First-line therapy consisted of percutaneous radiation of the tumor's primary region, which started two weeks after diagnosis of the lymphoepithelial carcinoma of the base of the tongue. Partial doses of 2 Gy up to an entire dose of 30 Gy were given. Concomitant chemotherapy including cisplatin and 5 -fluorouracil was applied on the first and the fifth day of therapy. Up to now no radiogenic side effects of grade 3 and grade 4 have appeared.

\section{Discussion}

Lymphoepithelial tumors are the most common carcinomas of the nasopharynx. They were first described as a separate entity in 1921 by Regaud [7] and Schmincke [8]. According to the WHO classification, 3 types of carcinomas of the nasopharynx are distinguished, while only the non-differentiated type is considered to be a Schmincke's tumor. This is located per definition in the nasopharynx. When a compounded tumor, consisting of two elements, namely low-differentiated squamous epithelium and lymphocytic infiltration, lies outside of the nasopharynx, one speaks of a lymphoepithelial type of a low-grade differentiated squamous epithelial carcinoma.

\section{Histology}

Regarded as one entity, this compounded tumor, consisting of two components, can present with a varied histological appearance. The low-grade differentiated squamous epithelial carcinoma is characterized by a deep infiltration of T-lymphocytes and 
lymphoblasts in the stroma. Malignant cells are barely identifiable in the routine HE colored slices [6]. In our case, it was possible to find evidence of activated virus genome in the tissue of the tumor.

\section{Epidemiology and Incidence}

The tumor is more prevalent in the African and Chinese population. It is three times more common in males than in females. The incidence of the tumor according to age peaks between 20 and 30 years of age, and after 60 years of age. A genetic component is probable. There is an association with HLA type (A2, A33, B46, B58). Often a dermatomyositis manifests paraneoplastically. In $75 \%$ of these cases, it is combined with a tumor of the nasopharynx.

\section{Pathogenesis}

The abundant occurrence of lymphatic tissue in the nasopharynx explains the common occurrence of extralymphatic lymphomas and extramedullary plasmocytomas (20\% of all malignomas of the nasopharynx) [10]. Waldeyer's ring consists of lymphoid tissue of the adenoids (pharyngeal tonsils), of lymphoid tissue around the pharyngeal openings of the Eustachian tubes (Gerlach's tonsils), the palatine tonsils as well as the lymphoid tissue of the soft palate and the posterior third or base of the tongue (lingual tonsils). Together, they form a circular threshold to the opening of the upper aerodigestive tract. Here is the initial locus of contact between inhaled or ingested exogenous antigen and the mucosa-associated lymphoid tissue (MALT) of the aerodigestive tract [11]. Tumors of the nasopharynx arise from tissue occurring here. Thereby, respiratory epithelium is replaced by squamous epithelium as a result of chronic infections (metaplasia) [10]. Its cellular immunity is clearly reduced by an imbalance of the T-cell function. An infection with the oncogenic Epstein Barr virus seems to play a particular role [5]. The reactivation of this virus could be triggered by this imbalance of the T-cell function. This can transform lymphocytes and stimulate permanent growth. It can also stimulate dysplastic growth of the cells of the squamous epithelium and lead to the formation of a papilloma.

\section{Differential Diagnosis}

The morphology of the non-differentiated subtype of the lymphoepithelial carcinoma is quite similar to the diffuse large-cell Non-Hodgkin lymphoma of the B-cell type. In single cases, successful differentiation is only possible by immunohistological investigation. One must also consider an alternative diagnosis of an existent lymphoepithelial carcinoma even in an untypical location.

\section{First-Line Therapy}

First-line therapy consists of primary radiation of the tumor's primary region and its lymphatic drainage channels. Concomitant chemotherapy can be applied. In case of cervical tumor spreading, a salvage neck dissection reduces the risk of local recurrence. 


\begin{tabular}{|c|c|c|c|}
\hline $\begin{array}{l}\text { Cose Reports in } \\
\text { una.ayly }\end{array}$ & $\begin{array}{l}\text { Case Rep Oncol 2010;3:77-82 } \\
\text { D0l: } 10.1159 / 000302139\end{array}$ & Published online: March 24, 2010 & $\begin{array}{l}\text { @ } 2010 \text { S. Karger AG, Basel } \\
\text { ISSN } 1662-6575 \\
\text { www.karger.com/cro }\end{array}$ \\
\hline
\end{tabular}

\section{Prognostic Factors}

Primary radiation of the tumor can only inhibit a regional spreading in few cases. By exploiting all therapy options, there is a 5-year survival rate of $60 \%$ in stage I (according to UICC classification) and II [10]. Furthermore, there is a 5 -year survival rate of $25 \%$ in stage III and IV [2].

\section{Conclusion}

Despite the tumor's rare manifestation outside of the nasopharynx and due to the importance of structural characteristics of Waldeyer's tonsillar ring, one must also consider the differentiated carcinoma of lymphoepithelial matrix. Especially due to the well-known early tumor spreading, the cervical lymph node swelling, on both sides, can be recognized as a possible early symptom.

Fig. 1. a A minor asymmetrical hyperplasia of the base of the tongue on the right side is documented. The larynx was without pathological findings. b The vocal cords are without pathological findings.
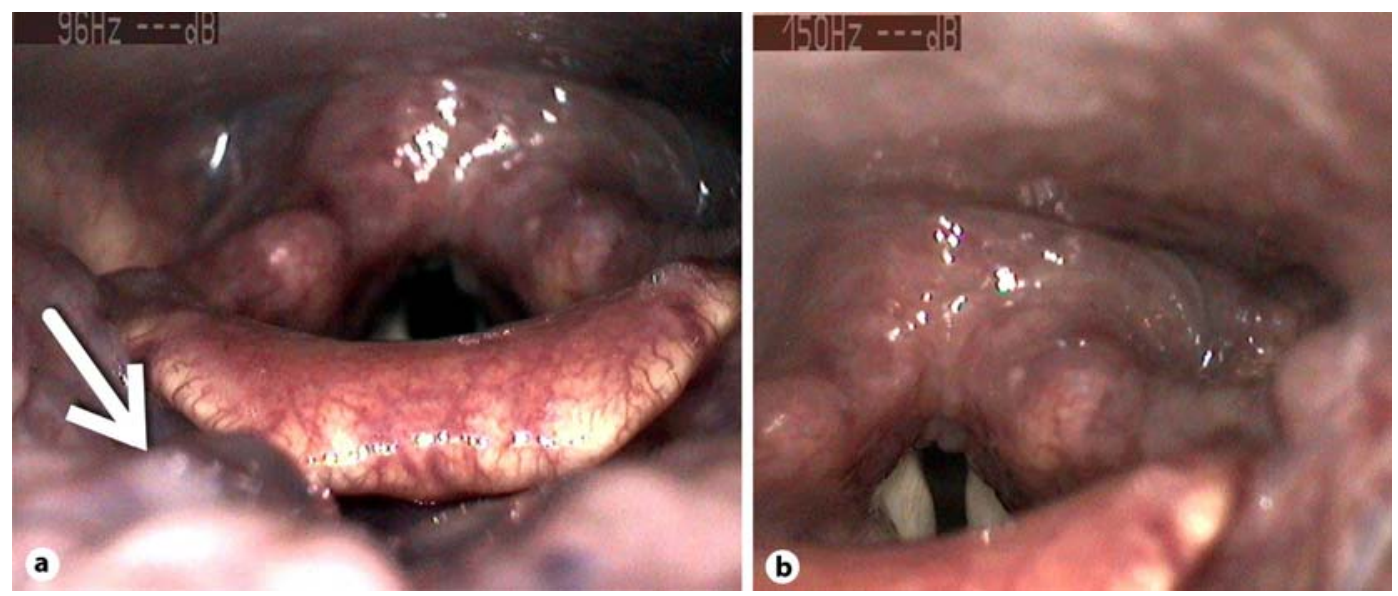


\begin{tabular}{c|l|l|l}
$\begin{array}{c}\text { Case Reports in } \\
\text { Onda.jy }\end{array}$ & $\begin{array}{l}\text { Case Rep Oncol 2010;3:77-82 } \\
\text { Dol: } 10.1159 / 000302139\end{array}$ & & $\begin{array}{l}\text { Published online: March 24, } 2010 \\
\text { ISSN 1662-6575 } \\
\text { www.karger.com/cro }\end{array}$ \\
\hline
\end{tabular}

Fig. 2. Lymphoepithelial mucosa (epithelial layer of the surface on the right side) with subepithelial infiltrations of atypical, blastary cells. HE, $\times 200$.

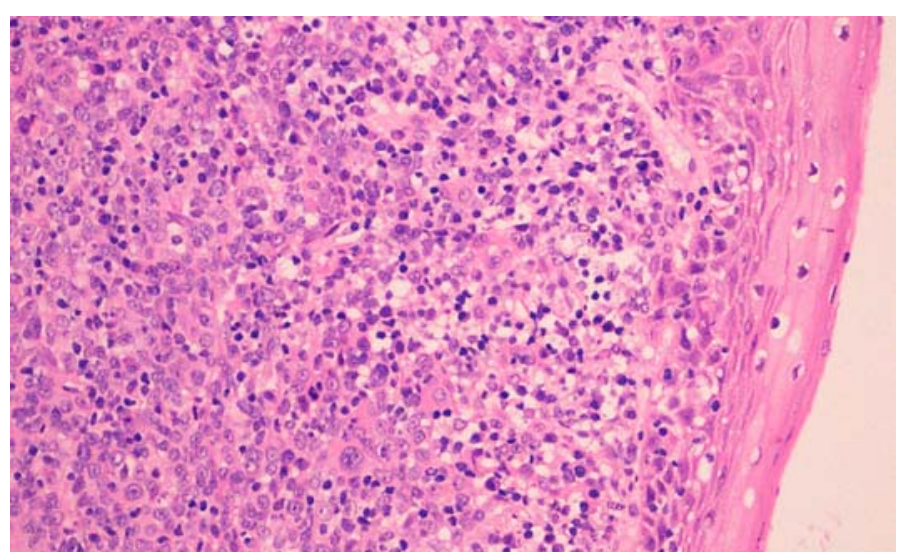

Fig. 3. The same region as in figure 2 is shown; the immunohistology shows that atypical cells of an epithelial nature are expressed. Immunohistology against pan-cytokeratin. $\times 200$.

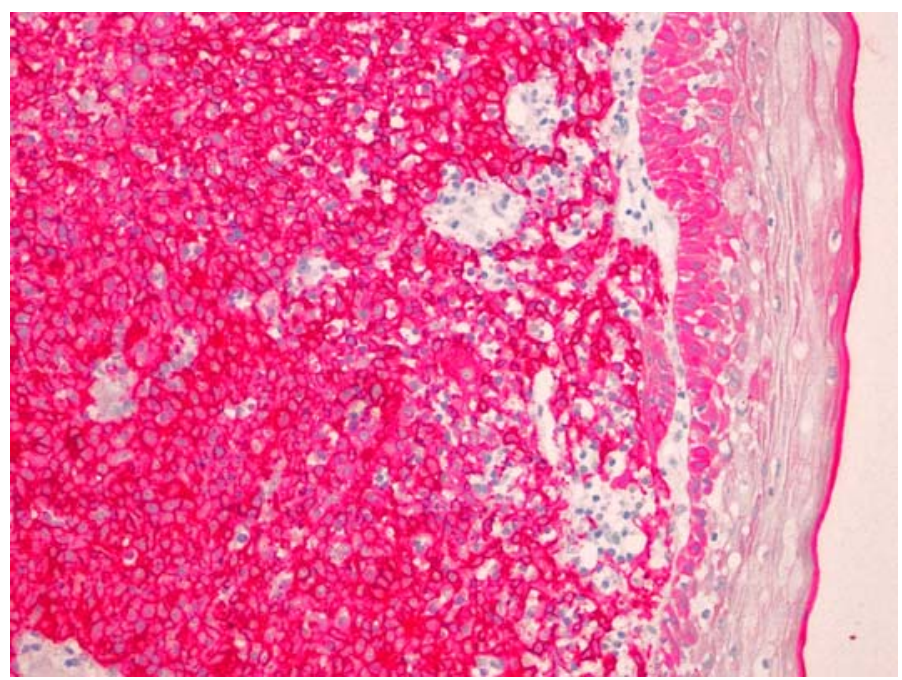




\section{References}

1 Bootz F, Keiner S, Weidenbach H: Das undifferenzierte Karzinom mit lymphzytärem Stroma im Kopf-Hals Bereich. Onkologe 1999;5:968-974.

2 Brennan B: Nasopharyngeal carcinoma. Orphanet J Rare Dis 2006;1:23.

-3 Clark MP, Westerberg BD, Berean KW: Primary middle ear Epstein-Barr virusrelated lymphoepithelial carcinoma: case reports and systemic review. Laryngoscope 2010;120:172-177.

4 Jung H, Park SK, Heo KW, Kang MS: Lymphoepithelial carcinoma of the maxillary sinus with orbital invasion. Auris Nasus Larynx 2009;36:487-490.

5 Lee JH, Kim SH, Han SH, An JS, Lee ES, Kim YS: Clinicopathological and molecular characteristics of Epstein-Barr virus-associated gastric carcinoma: a meta-analysis. J Gastroenterol Hepatol 2009;24:354-365.

6 Mahomed F, Grayson W: A rare case of lymphoepithelial carcinoma of the lip. Surg Oral Med Oral Pathol Oral Radiol Endod 2008;105:e49-e52.

7 Regaud C: Lympho-epitheliome de l'hypopharynx traité par la roentgenthérapie. Bull Soc Franc Otorhinolaryngol 1921;34:209-214.

8 Schmincke A: Über lymphoepitheliale Geschwülste. Beitr Pathol Anat 1921;68:161-170.

9 Schneider M, Rizzardi C: Lymphoepithelial lesions. Arch Pathol Lab Med 2008;132:278-282.

10 Strutz J, Mann W: Praxis der HNO-Heilkunde, Kopf- und Halschirurgie. 2. Auflage, Thieme Verlag, 2010, pp 478-480.

11 Tan LHC: Lymphomas involving Waldeyer's ring: placement, paradigms, peculiarities, pitfalls, patterns and postulates. Ann Acad Med Singapore 2004;33(4 suppl):15-26. 